\title{
THE COLLEGE'S COMMENTS ON THE REPORT OF THE COMMITTEE ON GHILD HEALTH SERVICES (COURT REPORT) Child and Adolescent Psychiatry
}

\section{Introduction}

The Royal College of Psychiatrists is very much in sympathy with the general tenor of the proposals put forward in the Report on Child Health Services regarding children and families and is impressed by the emphasis given to psychological and social aspects of child health.

In its request to the College for comments on the Report, the DHSS asked that particular attention should be paid to listed propositions underlying the Child Health Services Committee's key recommendations. Comments on these propositions are given below, followed by comments on other recommendations relating to child and adolescent psychiatry. The important proposals in the Report concerning the psychiatric care of mentally handicapped children are not discussed in this document. This matter is currently being considered by a Special Committee of the Council of the College and it is expected that a policy document will be agreed later in the year, which will contain proposals relevant to the Court Committee's recommendations. The College does, however, at this stage wish to make clear its concern and regret that no mention is made of the psychiatrist dealing with mentally handicapped children as a necessary member of the District Handicap Team.

Comments on Summarized Propositions Contained in the (Court) Report

\section{Report Proposition}

(a) The long-term aim should be to provide pre-school health services through general practitioner paediatricians.

\section{Comment}

The College sees the advantage of some degree of specialization among general practitioners and that the proposed change provides some sort of administrative solution to the delivery of school medical services. However, although not strongly opposed to the proposal, the College doubts the wisdom of separating the delivery of services to children from that delivered to the rest of the family as a matter of principle. It might be wiser to encourage the development of specialization in general practice to a less marked degree than that proposed in the report without the imposition of a blanket solution of this type. This view is taken bearing in mind that the concept of reorganization is in any case currently unpopular, and that reorganization could only be effective at a time when resources are less lacking than they are at present. It would be important to ensure that adequate training was available to those involved in the delivery of specialized care, and this would inevitably be expensive.

\section{Report Proposition}

(b) There should be a degree of specialization in health visiting, leading to the establishment of child health visitors.

Comment

The College welcomes this proposition and sees many advantages in it for the health and welfare of children.

\section{Report Proposition}

(c) There should be increased involvement of paediatricians in work in the community, including the establishment of posts for consultant community paediatricians.

\section{Comment}

The College welcomes this proposition in principle.

\section{Report Proposition}

(d) There should be district handicap teams with responsibility for all handicapped, including mentally retarded, children.

\section{Comment}

See Introduction to this document.

\section{Report Proposition}

(e) The child guidance and child psychiatric services should be integrated as a single child and adolescent service.

\section{Comment}

The College has for some time taken the view that division between hospital-based and communitybased ('Child Guidance') psychiatric services for children is unreal, and that children with psychiatric disorder have the same needs for assessment and treatment wherever they are seen. The College, therefore, welcomes this proposition warmly.

There are, however, anxieties about its implementation in relation to the service provided in the community in other than a health service setting. 
Matters of particular concern are:

(i) Exercise of medical responsibility

(ii) Administrative direction of the facility

(iii) Problems of confidentiality of documents

(iv) The need for assurances that premises belonging to authorities other than a health authority which are used for child psychiatry can continue to be used for this purpose

(v) The responsibility of the child psychiatric team for a comprehensive mental health service to the community and the manner in which this responsibility can be exercised.

It is also felt that psychologists should be able to work independently as members of their own departments (school psychological services) in such facilities as well as in a team as part of a child psychiatric service.

\section{Report Proposition}

(f) There is a need for a body at national level to look at the way children's needs are being met and to carry out the functions described in Chapter 16 of the Committee's Report, which might be fulfilled by a joint committee of the Personal Social Services Council and the Central Health Services Council.

\section{Comment}

The College does not really feel competent to judge the value of this proposal, but questions whether any committee at national level concerned with children's needs should not have statutory representation from a body concerned with education.

\section{Other Comments}

As well as commenting on the specific proposals to which the DHSS have particularly requested its view, the College would also wish to comment on various other views and recommendations expressed in the Report.

I. The College supports the view that levels of psychiatric staffing proposed many years ago have still not been achieved (15.8). The Report recommends a level of one child psychiatrist per 35,000 children, yet acknowledges that this is inadequate if the needs of preschool children, older adolescents, and the mentally handicapped are to be met (15.34). The College cannot accept the view of the Report that the more favourable rate mentioned (two full-time psychiatrists per 60,000 children) is impracticable, and would draw attention to its previously issued document on Norms for Medical Staffing of Psychiatric Services; Child Psychiatry* and The Psychiatry of Adolescencet, which provide a more up-to-date picture of the College's view on this matter than the 1960 RMPA document mentioned in the Report. It will be seen from Norms for Medical Staffing of Psychiatric Services; Child Psychiatry that in 1973 the College recommended a level of $1 \frac{1}{2}$ consultants and junior staff in training for 35,000 school children as a 'realistic minimum'.

2. The College notes the definition of 'psychiatric disorder' to include any condition where there is an 'abnormality of behaviour, emotions, or relationships', etc. (15.1). It is perhaps not made sufficiently clear in the Report that the use of the term 'psychiatric disorder' does not imply that all such problems need the intervention of a psychiatrist, and that care for a psychiatric disorder defined in this way can often appropriately be provided by members of other related professions.

3. The College strongly supports the view (15.21) that specialization of social workers in the child psychiatric field is desirable, and that there should be a 'further development of field work posts with teaching and consultative responsibility so that senior social workers of high calibre can remain in direct practice without loss of salary or status'.

4. The College agrees that 'some teaching of child psychiatry should be a mandatory part of undergraduate (medical) training' (15.24), but would point to the need for increased representation of child psychiatrists on teaching hospital staffs if this is to be realistically implemented.

5. The College endorses the view that non-medical child psychotherapists could make a more effective contribution if their training provided 'an awareness of other psychiatric techniques' complementary to their own (15.25 and 15.26). In connection with this Section, the College felt that more acknowledgement might have been made in the Report to the work carried out by occupational therapists who, outside the London area, are often providing the mainstay of nonmedical psychotherapeutic services to individual children and groups of children.

6. The College agrees that 'those professionals who care for children must be familiar with the needs and problems of mentally ill adults as they impinge

- News and Notes, December 1973

$\dagger$ News and Notes, September 1976 
on the family' (15.14), and suggests that the implementation of this recommendation would be facilitated by the nomination of child psychiatrists to Mental Health Care Planning Teams as well as to Child Health Care Planning Teams.

7. The College endorses the view (15.24) that general practitioners should receive training in child psychiatry.

8. The College agrees that there is a need for an improvement in the career structures of child and adolescent psychiatric nurses (15.38).

9. While agreeing with the Report's recommendation (15.44) that 'parents should be free to approach the (psychiatric) service directly' the College feels that the general practitioner should be informed unless it seems that there are very good reasons against this.

10. The College endorses the view (15.45) that 'out-patient services for children should be developed on the basis of a well-integrated inter-disciplinary team providing a co-ordinated service', and that to achieve this there is a need for continuity so that the same individuals can work together regularly over a period of time.

II. The College supports the view that grave deficiencies exist particularly in residential psy- chiatric services for the adolescent age group (15.55), and has already made recommendations on this subject.

12. In the same document (The Psychiatry of Adolescence) the College has recently taken a somewhat different view from that expressed in the Report on the delivery of psychiatric services. Although it is agreed that there are certain advantages in a system whereby younger adolescents are cared for by psychiatrists dealing mainly with children and older adolescents by those dealing with adults, it is nevertheless the continuing view of the College (as expressed in the recent memorandum) that it is essential that a certain number of psychiatrists should work whole time in the field of adolescent psychiatry.

I3. The College endorses the recommendations in the Report ( $15.6 \mathrm{r}$ ) concerning the special needs of adolescents with chronic psychiatric disorder, and particularly supports the view that there is a need for increased hostel accommodation for such youngsters.

[These comments were prepared by a Special Committee under the chairmanship of Professor Philip Graham. Comments on those parts of the Report relevant to Mental Handicap are under consideration and will be published in a later issue.]

\section{M.R.G.PSYGH. EXAMINATIONS-AUTUMN 1977}

The next M.R.C.Psych. Examinations will take place on the following dates:

Preliminary Test-Wednesday 5 October 1977

Membership Examination (Written Papers)Wednesday 9 November 1977

Membership Examination (Clinical and Oral)Monday 14 to Wednesday 16 November 1977

The entry fees are $£_{25}$ (resit $£_{15}$ ) and $£_{35}$ (resit £25) respectively.

The closing date for receipt of entries is WEDNESDAY 7 SEPTEMBER 1977.

Prospective candidates are reminded that late entries will not be accepted and that the College no longer gives exemption from any part of the Examinations. Candidates who were previously granted exemption from the Preliminary Test (i.e. before June 1973) are reminded that they must pass the Membership Examination within five years from the date of granting in order to retain their exemption.

In cases where candidates have undertaken parttime or overseas experience in psychiatry, or are required to submit the name and address of their Clinical Tutor or Consultant Ghief, the entry forms should be submitted at least three weeks in advance so that the application may be finalized before the closing date is reached.

Regulations and application forms are obtainable from the Examinations Secretary at 17 Belgrave Square, London SWIX 8PG. Past Essay Question Papers are available at 5op per set covering five years, and a Reading List at $38 \mathrm{p}$ both including postage, which amounts must be prepaid.

All Members and Fellows are asked to bring this announcement to the notice of any prospective candidates who may be working under their guidance. 